\title{
MAIORIDADE NO DIREITO CIVIL PORTUGUÊS E BRASILEIRO: UMA BREVE ANÁLISE A PARTIR DO DIREITO COMPARADO
}

\author{
MAJORITY IN PORTUGUESE AND BRAZILIAN CIVIL LAW: A BRIEF ANALYSIS \\ FROM COMPARATIVE LAW
}

André Luis Alves de Quevedo ${ }^{1}$

\begin{abstract}
RESUMO: O objetivo do presente trabalho foi realizar um estudo da maioridade no Direito Civil português e brasileiro, a partir do Direito Comparado. Foram realizadas buscas no Código Civil brasileiro de 2002 (Lei $\mathrm{N}^{\circ}{ }_{10.406}$, de ro de janeiro de 2002) e Código Civil português de 1966 (Decreto-Lei № 47344, de 25 de novembro 1966). Além disso, foram selecionados textos acadêmicos sobre o tema, a fim de qualificar a discussão. $\mathrm{Na}$ construção do texto foram utilizados elementos de macrocomparação e micro comparação. Atualmente, em Portugal a maioridade se atinge aos 18 anos, assim como no Brasil. E, no território português, a única exceção para cessar a minoridade é com o casamento a partir dos $\mathrm{I} 6$ anos. No caso brasileiro, ainda existem os critérios de emancipação para o atingimento da maioridade, conforme o artigo $5^{\circ}$ do Código Civil; o que no Direito de Portugal já foi revogado desde 1977. Ganha relevância o destaque das exposições de motivos (no preâmbulo das leis) que alteram o Código Civil português, pois isso permite entender a evolução da norma no tempo. Talvez esse seja um aprendizado de técnica legislativa que podemos considerar do ordenamento jurídico de Portugal, em termos de Direito Comparado, para o ordenamento jurídico brasileiro.
\end{abstract}

Palavras-chave: Direito Comparado. Maioridade. Emancipação. Direito Civil.

ABSTRACT: The objective of the present paper was to carry out a study of the age of majority in the Portuguese and Brazilian Civil Law, based on Comparative Law. Searches were carried out in the Brazilian Civil Code of 2002 (Law No.10,406, of January Io, 2002) and Portuguese Civil Code of 1966 (Decree-Lei No. 47344, of November 25, 1966). In addition, academic texts on the subject were selected in order to qualify the discussion. In the construction of the text, macrocomparison and microcomparison elements were used. Currently, in Portugal the age of majority is 18 years old, equally in Brazil. And, in the Portuguese territory, the only exception to terminate minority is with marriage from 16 years of age. In the Brazilian case, there are still emancipation criteria for reaching adulthood, according to article 5 of the Civil Code; which in the Portuguese Law has already been revoked since 1977. The explanatory statement (in the preamble of the laws) that alter the Portuguese Civil Code gains relevance, as this allows us to understand the evolution of the rule over

\footnotetext{
I Mestre em Epidemiologia pela Universidade Federal do Rio Grande do Sul (UFRGS). Bacharel em Direito pela UFRGS. Especialista em Saúde na Secretaria da Saúde do Estado do Rio Grande do Sul.
} 
time. Perhaps this is an apprenticeship in legislative technique that we can consider from the Portuguese legal system, in terms of Comparative Law, to the Brazilian legal system.

Keywords: Comparative Law. Majority. Emancipation. Civil Right.

\section{INTRODUÇÃO}

O Direito Comparado é uma disciplina jurídica que tem por objeto a comparação sistemática de direitos, visando identificar e explicar as semelhanças e diferenças entre as ordens jurídicas estudadas (JERÓNIMO, 2015). Reflete Fernandes (2021, p. 198) que, “[...] a importância do Direito comparado aumentou enormemente na atualidade, marcada pela internacionalização e pela globalização”.

Para Ovídio (1984, p. I6I), “A pesquisa jurídica comparativista contribui de forma marcante para a evolução e o alargamento das fronteiras do conhecimento jurídico.”. Quanto às funções do Direito Comparado, Ovídio sinaliza que a disciplina tem um caráter prático e instrumental (superando a crítica de "mero diletantismo intelectual)", tendo impacto na Ciência do Direito, no plano político, econômico e outros campos (OVÍDIO, I984, p. I65).

Segundo Dutra (2016, p. 206), "O grande desafio, hoje, para o comparatista, é realizar um trabalho metodológico que seja, ao mesmo tempo, rigoroso e capaz de transitar entre os diversos métodos existentes.". Ainda, segundo o autor, tal "dificuldade é acentuada pela característica natural de interdisciplinaridade que todo estudo comparado contém.” (DUTRA, 2016, p. 206).

Assim na realização da presente pesquisa foram realizadas buscas no Código Civil brasileiro de 2002 (Lei $\mathrm{N}^{\circ}$ Io.406, de io de janeiro de 2002) e Código Civil português de I966 (Decreto-Lei № 47344, de 25 de novembro 1966). Além disso, foram selecionados textos acadêmicos que versassem sobre o tema, a fim de qualificar a discussão. Nessa seara, o objetivo do presente trabalho foi realizar um estudo da maioridade no Direito Civil português e brasileiro a partir do Direito Comparado.

Cabe destacar que o Código Civil de Portugal passou por 78 atualizações, estando na sua $79^{\text {a }}$ versão (Lei № 65, de 04 de novembro de 2020). Assim, para a análise da presente pesquisa foi utilizada a última versão. Já no caso brasileiro, o primeiro Código 
Civil foi publicado em 1916, com a Lei $\mathrm{N}_{3}^{3}$.071, de Io de janeiro de 1916 (revogada), e o atual Código Civil brasileiro, em vigor desde 2002, foi positivado com a Lei $\mathrm{N}^{\circ}{ }_{10.406}$, de ro de janeiro de 2002.

No desenvolvimento do trabalho, com abordagem de Direito Comparado, foram utilizados elementos de macrocomparação, visando apresentar as diferenças fundamentais entres os sistemas jurídicos dos países estudados (como origem histórica, estruturas fundamentais, fontes do direito, autoridade das decisões judiciais, quem são os operadores do direito e qual a sua formação). Já na parte de microcomparação foram realizadas comparações do instituto jurídico nas diferentes ordens jurídicas.

\section{ELEMENTOS DE MACROCOMPARAÇÃO: ORDENAMENTOS JURÍDICOS COIRMÃOS?}

Desde o domínio do Reino de Portugal sobre o Brasil, incluindo o período posterior de independência,

[...] o Direito Português penetrou no Brasil, onde, durante vários séculos, teve vigência $e$, hoje, conserva uma influência particularmente importante que permite afirmar, sem a mínima ousadia, que partilhamos, Portugueses e Brasileiros, do mesmo direito: o direito luso-brasileiro." (JUSTO, 2008, p. 197).

Savick (2009, p. 2I), reflete que, “A independência política brasileira com relação a Portugal não significou, necessariamente, a independência jurídica.”. Para a autora, “[...] mesmo com a tentativa de formação de um Direito brasileiro próprio, muito do que lhe foi trazido de Portugal se manteve, ainda que já modificado na matriz.” (SAVICK, 2009, p. 13).

Nesse sentido, estudos de Direito Comparado sobre estes ordenamentos jurídicos podem ajudar a identificar de que forma a aplicação do Direito foi evoluindo no território português e brasileiro.

No Brasil, assim como o Direito de Portugal, utiliza-se a "[...] família jurídica romano-germânica, onde Direito é organizado em códigos [...]” (FERNANDES, 202I, p. 198). E, a lei escrita é a fonte principal do Direito, complementada pela jurisprudência, pelos Princípios Gerais do Direito, pela doutrina, pela analogia e pelo direito consuetudinário (fontes secundárias).

Consoante Sifuentes (1999, p. 328), na Constituição Cidadã (Constituição da 
República Federativa do Brasil de 1988), após 2I anos de ditadura militar, na estruturação do Poder Judiciário, no título da "Organização dos Poderes" (Título IV), artigos 92 a I26, o legislador brasileiro especificou quase exaustivamente seus órgãos integrantes, sendo eles: I - o Supremo Tribunal Federal (STF); I-A o Conselho Nacional de Justiça; II - o Superior Tribunal de Justiça (STJ); II-A - o Tribunal Superior do Trabalho; III - os Tribunais Regionais Federais e Juízes Federais; IV - os Tribunais e Juízes do Trabalho; V - os Tribunais e Juízes Eleitorais; VI - os Tribunais e Juízes Militares; VII - os Tribunais e Juízes dos Estados e do Distrito Federal e Territórios (BRASIL, I988).

Além deste também são operadores do Direito os profissionais que atuam no Ministério Público, na Defensoria Pública e na advocacia privada. Em resumo todos operadores do Direito são bacharéis, ou seja, possuem formação universitária (nível superior) e para ingressarem na carreira de advogado devem ser aprovados em exame da Ordem dos Advogados do Brasil. $\mathrm{Na}$ área do Direito, grande parte dos funcionários públicos para ingressarem na Administração Pública realizam concurso público. Já os profissionais que atuam em atividades administrativas (de suporte ao Poder Judiciário, Ministério Público e Defensoria Pública) podem ter nível superior ou não e geralmente ingressam por concurso público, de acordo com o artigo 37 da Constituição da República Federativa do Brasil de 1988. Cabe destacar ainda que, as decisões judiciais do STF e STJ têm efeito vinculante no ordenamento jurídico brasileiro.

No caso de Portugal, a atual Constituição da República Portuguesa, vigente desde o dia 25 de abril de 1976 , com 296 artigos,

[...] não utilizou a denominação Poder Judiciário. Preferiu o legislador constituinte elencar, na parte relativa à "Organização do Poder Político", ao lado do Presidente, da Assembléia da República e do Governo, os Tribunais como "órgãos de soberania com competência para administrar a Justiça em nome do povo. (SIFUENTES, i999, p. 330).

Nesse sentido, no País é adotado o "[...] sistema de dualidade de jurisdição (administrativa e judicial)” (SIFUENTES, 1999, p. 330). Ainda, segundo a autora,

A organização judiciária portuguesa compreende, para além do Tribunal Constitucional, as seguintes categorias de Tribunais: a) o Supremo Tribunal de Justiça e os tribunais judiciais de primeira e de segunda instância (Relações); b) o Supremo Tribunal Administrativo e os demais tribunais administrativos e fiscais; c) o Tribunal de Contas; d) Tribunais marítimos e; e) Tribunais arbitrais e julgados de paz (art. 209, I e 2, CRP). A Constituição proíbe a existência de tribunais especiais ou de exceção, salvo os militares, para o julgamento de certas 
categorias de crimes (art. 209, 4). (SIFUENTES, 1999, p. 330),

Para ser advogado em Portugal é necessário cursar Universidade (Licenciatura em Direito) pelo período de quatro anos (240 créditos - oito semestres), realizar estágio profissional, ser aprovado em prova de conhecimentos específicos em Direito (prova de agregação) e realizar a inscrição na Ordem dos Advogados do País. Na página da Faculdade de Direito, da Universidade de Lisboa lê-se que:

\begin{abstract}
Os graduados em Direito têm possibilidade de escolher várias profissões jurídicas. De entre as áreas profissionais destacam-se a advocacia, magistratura, consultoria jurídica, consultoria fiscal e financeira, mediação jurídica e arbitragem, docência, carreira diplomática, acesso a cargos públicos em organizações internacionais, registos e notariado, solicitadoria, oficiais de justiça, agentes de execução, inspetores e coordenadores da Polícia Judiciária, cargos de direção e de gestão empresarial, investigação jurídica e histórica, dirigentes e quadros superiores da administração pública.
\end{abstract}

Em suma, percebe-se que a carreira jurídica de Portugal é parecida com a do Brasil. Destaca-se ainda que, desde 2003 pelo acordo de reciprocidade entre Brasil e Portugal, advogados dos países podem atuar nos dois territórios - no território brasileiro tal acordo está positivado no Provimento $\mathrm{N}^{\circ}$ 129, de 08 de dezembro de 2008 da Ordem de Advogados do Brasil (BRASIL, 2009), sendo pautado no Tratado de Amizade, Cooperação e Consulta, entre a República Federativa do Brasil e a República Portuguesa. Em, Portugal "Essa previsão é expressa no Artigo 201 do Estatuto da Ordem dos Advogados e nos artigos i7 a I9 do RIAAR (Regulamento de Inscrição de Advogados e Advogados Estagiários)” (NELB, [2021]).

\title{
MICROCOMPARAÇÃO: REFLEXÕES SOBRE A MAIORIDADE NOS ORDENAMENTOS JURÍDICOS COMPARADOS
}

Conforme Sidou (2004, p. 125), “Todo ser humano é titular de direitos a partir do nascimento, mas só se torna capaz de exercitá-los por si depois de transitar pela incapacidade (minoritas), cujo fator natural é o tempo de vida.”. Segue o autor historicizando que:

No direito romano, retrato dos regimes jurídicos incipientes, a minoritas esteve primitivamente baseada na maturidade sexual natural, quatorze anos para o homem, doze para a mulher. Foi no intuito de proteger os adolescentes, por essa forma tornados capazes muito cedo, que a lex Plaetoria (ou Laetoria) de 191 ou 200 a.C. tornou passíveis de rescisão os negócios com os menores que lhes resultasse transação ruinosa, para tanto estabelecendo como limite dessa proteção a idade de 
25 anos. (SIDOU, 2004, p. 125).

Afirma o autor que a marca etária de 25 anos permaneceu nos códigos portugueses - nas Ordenações Afonsinas (I447) e Filipinas (I603) - até os tempos modernos. Refere ainda que, as Ordenações Filipinas regeram o Direito Civil brasileiro até a edição do seu primeiro Código Civil (Lei No 3.071, de Io de janeiro de 1916 - hoje revogada). Todavia, com a Lei de 3I/ro/ı831, a menoridade no Brasil foi reduzida para 2i anos, acompanhando o modelo francês expresso no Código de Napoleão de 1804, conforme o artigo 488 desse documento jurídico (SIDOU, 2004, p. 125-126).

No Direito do Brasil, a partir do Código Civil de 2002 a maioridade dá-se quando se atinge a idade de 18 anos. A partir desse momento, a pessoa tem a plenitude da capacidade civil, e a relação com os pais será regida, juridicamente, pelo dever de solidariedade entre os membros da família - e não mais pelos deveres e direitos do poder familiar.

Outras formas equiparadas de maioridade são: o casamento e a capacidade de desenvolver economia própria (a partir dos 16 anos e com o consentimento de ambos os pais, um pai na falta do outro ou decisão judicial por divergência entre os pais), colação de grau em nível superior, o exercício de emprego público e a emancipação propriamente dita (independente da realização de atividades financeiras). Sinaliza-se que, uma vez concedida, a emancipação não pode ser revogada e o menor passa a ter plena capacidade para a vida civil. Nessa linha, o artigo $5^{\circ}$ da Lei $\mathrm{N}^{\circ}$ Io.406, de io de janeiro de 2002 (Código Civil) traz as hipóteses que fazem cessar a menoridade no Brasil:

Art. $5^{\circ}$ A menoridade cessa aos dezoito anos completos, quando a pessoa fica habilitada à prática de todos os atos da vida civil.

Parágrafo único. Cessará, para os menores, a incapacidade:

I - pela concessão dos pais, ou de um deles na falta do outro, mediante instrumento público, independentemente de homologação judicial, ou por sentença do juiz, ouvido o tutor, se o menor tiver dezesseis anos completos;

II - pelo casamento;

III - pelo exercício de emprego público efetivo;

IV - pela colação de grau em curso de ensino superior;

$\mathrm{V}$ - pelo estabelecimento civil ou comercial, ou pela existência de relação de emprego, desde que, em função deles, o menor com dezesseis anos completos tenha economia própria (BRASIL, 2002).

Em relação ao casamento, o artigo 1.517 do Código Civil brasileiro de 2002 dispõe 
que:

“[...] O homem e a mulher com dezesseis anos podem casar, exigindo se autorização de ambos os pais, ou de seus representantes legais, enquanto não atingida a maioridade civil.”. Ainda, conforme a inteligência do parágrafo único do supracitado artigo, "Se houver divergência entre os pais, aplica-se o disposto no parágrafo único do art. I.63i.” (BRASIL, 2002).

Relevante destacar que é proibido o casamento de menores de 16 anos no Brasil, com ou sem consentimento dos pais e/ou responsáveis (tutores), pois a partir da Lei № 13.8II, de I2 de março de 2019 foi alterado o artigo 1.520 do Código Civil Brasileiro de 2002 sendo somente permitido casamento a partir dos 16 anos, com anuência dos pais ou responsáveis ou do juiz, conforme o artigo $5^{\circ}$ do Código Civil Brasileiro de 2002.

Importante destacar que, o Estatuto da Criança e do Adolescente (Lei № 8.o69, de I3 de julho de 1990), no artigo 148, traz que: “A Justiça da Infância e da Juventude é competente para: $[\ldots]$ c) suprir a capacidade ou o consentimento para o casamento; [...] e) conceder a emancipação, nos termos da lei civil, quando faltarem os pais;" (BRASIL, 1990).

Ainda cumpre sinalizar que, antes da Lei № 13.8II a redação vigente do artigo 1.520 do Código Civil Brasileiro de 2002 era a seguinte: “Excepcionalmente, será permitido o casamento de quem não alcançou a idade núbil (art. I.517), para evitar imposição ou cumprimento de pena criminal ou em caso de gravidez.”. Ou seja, por essa exceção, a emancipação pelo casamento não tinha um viés econômico (como o atual) e sim de conotação sexual.

Já a emancipação é ato de vontade dos pais para que o filho maior de 16 e menor de I8 exerça de forma plena sua capacidade negocial. Deve ser feita por instrumento público (artigo 9º, inciso II do Código Civil brasileiro), sem necessidade de homologação judicial. Depende da concordância de ambos os pais, pois não se pode emancipar o adolescente somente em relação a um deles. Havendo divergência sobre isto, é possível buscar o Poder Judiciário, para que seja suprido o consentimento do pai discordante, demonstrando-se que sua negativa foi injustificada, conforme o artigo 1.69o do Código Civil brasileiro:

Art. I.69o. Compete aos pais, e na falta de um deles ao outro, com exclusividade, representar os filhos menores de dezesseis anos, bem como assisti-los até completarem a maioridade ou serem emancipados.

Parágrafo único. Os pais devem decidir em comum as questões relativas aos 
filhos e a seus bens; havendo divergência, poderá qualquer deles recorrer ao juiz para a solução necessária (BRASIL, 2002).

Pelos ensinamentos de Sidou (2004, p. 128), temos por origem do termo emancipação e emancipação antecipada o seguinte:

\begin{abstract}
$\mathrm{O}$ ingresso na maioridade leva o expressivo nome de emancipação. É oriundo do arcaico instituto do mancipium, ato do adquirente da res (escravo) tomá-la na mão, para formalizar a propriedade. O derivado mancipatio, - onis precedido do prefixo negativo (ex), passou a designar o opositivo, a perda dessa propriedade, ou a cessação de qualquer dependência de outrem [...] $\mathrm{O}$ direito romano consagrou essa emancipação antecipada com o nome de venia aetatis, ou a favor da idade. Instituto formalizado por Constantino (Codex, 2.44,2), porém que se costumava atribuir a Septimo Severo (anos 193-2II, um século antes), a venia aetatis era um benefício do príncipe, outorgado a quem, havendo completado os 20 anos, quando homem, I8 anos, quando mulher, solicitasse a dispensa da incapacidade pupilar, demonstrando, por meio de testemunhos, bons costumes, probidade e vida honesta. Consistia, portanto, num favor imperial, deferido ante cada postulação, o que, uma vez obtida, propiciava ao menor investir, por si próprio, nos atos da vida civil.
\end{abstract}

Segundo entendimento doutrinário, no Direito Civil brasileiro a emancipação ocorre “[...] por concessão dos pais, homologada pelo juiz, se o menor tiver i6 anos completos (CC, art. $5^{\circ}$, parágrafo único, I). Mas pode ela decorrer, automaticamente, de certas situações ou fatos previstos no aludido art. $5^{\mathfrak{o}}$, parágrafo único, II a V.”. Ainda segundo o autor, "A maioridade faz cessar inteiramente a subordinação aos pais." (GONÇALVES, 2021, p. 170).

No Direito de Portugal, conforme Artigo 130.ํ, que trata dos efeitos da maioridade, na Subsecção II (Maioridade e emancipação) lê-se que: “Aquele que perfizer dezoito anos de idade adquire plena capacidade de exercício de direitos, ficando habilitado a reger a sua pessoa e a dispor dos seus bens.” (PORTUGAL, 1977). Ainda, de acordo com o Artigo 129.. , que trata sobre o termo da incapacidade dos menores, "A incapacidade dos menores termina quando eles atingem a maioridade ou são emancipados, salvas as restrições da lei.” (PORTUGAL, 1977). Complementarmente, dispõe o Artigo 131.o que: "Estando pendente contra o menor, ao atingir a maioridade, ação de acompanhamento, mantêm-se as responsabilidades parentais ou a tutela até ao trânsito em julgado da respetiva sentença".

Cabe destacar que, até o Decreto-Lei № 496, de 25/II/1977, a redação vigente no código civil português era a seguinte: "Aquele que perfizer vinte e um anos de idade adquire plena capacidade de exercício de direitos, ficando habilitado a reger a sua pessoa e 
a dispor dos seus bens." (PORTUGAL, 1966), ou seja, a redução da maioridade de 2i para I8 anos no Direito de Portugal deu-se em 1977, onze anos após entrar em vigência o Código Civil português de ig66. Para a alteração da maioridade no Código Civil português são apontadas as seguintes exposições: a compatibilização com a Constituição de Portugal; a utilização do Direito Comparado, especialmente de ordenamentos jurídicos europeus; e a recomendação do Conselho da Europa, conforme pode ser lido abaixo:

\begin{abstract}
No que respeita ao título II da parte geral, destaca-se a antecipação da maioridade para os dezoito anos (artigos 122. ํ e seguintes). Esta solução decorre indirectamente da própria Constituição, na medida em que reflecte o alinhamento com a idade fixada pela lei fundamental para a aquisição da capacidade eleitoral activa e passiva: podendo-se ser deputado com dezoito anos, mal pareceria que continuasse a entender-se que só depois dessa idade se adquiria plena capacidade para reger a própria pessoa e dispor dos próprios bens. Mas não é apenas o preceito constitucional que justifica esta modificação: o direito comparado aponta decididamente no mesmo sentido. $\mathrm{Na}$ verdade, assiste-se hoje em toda a Europa - e mesmo fora dela - a um movimento que defende a redução da idade da maioridade civil, tendendo as legislações e projectos mais recentes para a situar nos dezoito anos. Foi a solução consagrada pela lei francesa de 1974, pela lei da República Federal da Alemanha do mesmo ano, pela lei italiana de 1975, como já o fora pela lei inglesa em 1969. É a solução também acolhida nas leis sueca e dinamarquesa, e a que vigora na generalidade dos países do Leste europeu. O Conselho da Europa recomendou recentemente aos países membros a fixação dos dezoito anos como início da maioridade. Na base desta opção, está o reconhecimento de que os jovens se acham hoje sujeitos a um mais rápido processo de desenvolvimento psíquico e cultural. Reivindicaram - e obtiveram já, em alguns sectores - uma autonomia a que deve corresponder a inerente responsabilidade. A solução proposta não será, por certo, isenta de inconvenientes. Mas estes ficam minimizados em confronto com as vantagens (PORTUGAL, 1977).
\end{abstract}

A emancipação no Direito Português está prevista no artigo I32: “[...] O menor é, de pleno direito, emancipado pelo casamento.”. Em relação aos efeitos da emancipação, segue o artigo 133 do Código Civil português dispondo que, “A emancipação atribui à menor plena capacidade de exercício de direitos, habilitando-o a reger a sua pessoa e a dispor livremente dos seus bens como se fosse maior, salvo o disposto no artigo i649." (PORTUGAL, 1977). Conforme o Artigo 1649. ${ }^{\circ}$ ipsis litteris:

I. O menor que casar sem ter obtido autorização dos pais ou do tutor, ou o respectivo suprimento judicial, continua a ser considerado menor quanto à administração de bens que leve para o casal ou que posteriormente lhe advenham por título gratuito até à maioridade, mas dos rendimentos desses bens ser-lhe-ão arbitrados os alimentos necessários ao seu estado. 2. Os bens subtraídos à administração do menor são administrados pelos pais, tutor ou administrador legal, não podendo em caso algum ser entregues à administração do outro cônjuge durante a menoridade do seu consorte; além disso, não respondem, nem antes 
nem depois da dissolução do casamento, por dívidas contraídas por um ou ambos os cônjuges no mesmo período. (PORTUGAL, 1977).

No Artigo 1877. do Código Civil de Portugal, que trata sobre a duração das responsabilidades parentais, está positivado que: "Os filhos estão sujeitos às responsabilidades parentais até à maioridade ou emancipação.”. Ainda, destaca-se que os artigos da emancipação por concessão dos pais ou do conselho de família (Artigo 134.ํo), a emancipação resultante de decisão judicial (Artigo $135 .^{\circ}$ ), a emancipação restrita (Artigo 136.ํ) e a revogação da emancipação (Artigo 137.을 ) foram revogados pelo Decreto-Lei № 496, de 25/II/1977. Assim, percebe-se que, o legislador português, naquele momento, optou por deixar o instituto da emancipação condicionado a idade de 18 anos, conforme pode ser lido nas exposições de motivos do referido Decreto-Lei № 496, de 25/II/1977:

\begin{abstract}
A fixação da maioridade aos dezoito anos colocou o problema de saber se deveria manter-se o instituto da emancipação por concessão (dos pais ou do conselho de família) ou por decisão do tribunal, a partir de uma idade inferior - por exemplo, a partir dos dezasseis anos. Admitiu-o recentemente a lei francesa, embora dentro de um condicionalismo apertado. Pareceu, porém, preferível afastar esta solução em termos gerais - assim o fizeram também a República Federal da Alemanha e a Itália - por não se afigurar razoável atribuir ao menor, abaixo dos dezoito anos, a capacidade de agir que a emancipação envolve (PORTUGAL, 1977).
\end{abstract}

Conforme Sidou (2004, p. 130), no caso do Direito de Portugal o casamento

desfeito não retorna o menor emancipado ao status de menoridade, ou seja, “[...] o casamento produz efeito idêntico à quitação da capacidade plena, é irrestrita e irrevogável.”. O mesmo ocorre no Direito Civil do Brasil.

\title{
CONSIDERAÇÕES FINAIS
}

Pela análise do Código Civil de Portugal de 1966 foi possível observar como o ingresso na maioridade foi modificado naquele País, considerando o fator etário; bem como se deu a revogação do instituto da emancipação. Ganha relevância o destaque das exposições de motivos (no preâmbulo das leis) que alteram o Código Civil português, pois isso permite entender a evolução da norma no tempo.

No caso do Direito brasileiro, as leis que alteram o Código Civil não trazem a exposição de motivos. Nesse sentido, para saber a motivação das alterações é necessário recorrer ao Projeto de Lei, o qual muitas vezes acaba sendo modificado no Congresso Nacional (Senado Federal e Câmara dos Deputados), sem que se apresente uma 
compilação final dos motivos para a alteração no referido texto legal. Talvez, esse seja um aprendizado de técnica legislativa que podemos considerar do ordenamento jurídico de Portugal, em termos de Direito Comparado para o ordenamento jurídico brasileiro.

Em suma, os principais achados relacionados ao objetivo do trabalho foram: em Portugal a maioridade se atinge aos 18 anos, assim como no Brasil. E no território português, a única exceção para cessar a minoridade é com o casamento a partir dos i6 anos. No caso brasileiro, ainda existem os critérios de emancipação para o atingimento da maioridade, conforme o artigo $5^{\circ}$ da Lei $\mathrm{N}^{\circ}{ }_{10.406}$, de ro de janeiro de 2002 (Código Civil) o que no Direito de Portugal já foi revogado desde 1977.

\section{REFERÊNCIAS BIBLIOGRÁFICAS}

BRASIL. Presidência da República. Casa Civil. Subchefia para Assuntos Jurídicos. Lei $\mathrm{N}_{3.071}$, de Io de janeiro de 1916 (revogada). Diário Oficial da União, I jan. 1916. Brasília, DF, 1916. Disponível em: http://www.planalto.gov.br/ccivil_03/leis/13071.htm. Acesso em: ro jun. 2021.

BRASIL. Presidência da República. Casa Civil. Subchefia para Assuntos Jurídicos. Constituição da República Federativa do Brasil de 1988. Diário Oficial da União, ı9ı-A, o5 out. 1988, p. I. Brasília, DF, i988. Disponível em: http://www.planalto.gov.br/ccivil_03/constituicao/constituicao.htm. Acesso em: I2 jun. 2021 .

BRASIL. Presidência da República. Casa Civil. Subchefia para Assuntos Jurídicos. Lei № 8.069, de 13 de julho de 1990. Diário Oficial da União, i6 jul. 1990, p. 13563. Brasília, DF, 1990. Disponível em: http://www.planalto.gov.br/ccivil_03/leis/18069.htm. Acesso em: I2 jun. 2021.

BRASIL. Presidência da República. Casa Civil. Subchefia para Assuntos Jurídicos. Decreto № 3.927, de 19 de setembro de 200I. Diário Oficial da União, 20 set. 200I, p. 4. Brasília,

DF, 2001 .

Disponível

em: 
http://www.planalto.gov.br/ccivil_03/decreto/200I/d3927.htm. Acesso em: I3 jun. 2021.

BRASIL. Presidência da República. Casa Civil. Subchefia para Assuntos Jurídicos. Lei $\mathrm{N}^{\circ}$ Io.406, de io de janeiro de 2002. Diário Oficial da União, II jan. 2002, p. I. Brasília, DF, 2002. Disponível em:

http://www.planalto.gov.br/ccivil_03/leis/2002/lio406compilada.htm. Acesso em: o8 jun. 2021.

BRASIL. Ordem dos Advogados do Brasil. Conselho Federal. Conselho do Pleno. Provimento № 129/2008. Diário da Justiça, I2 mar. 2009, p. 224, Brasília, DF, 2009. Disponível em: https://www.oabsp.org.br/noticias/2009/03/17/Provimento\%20129.2008.pdf. Acesso em: 13 jun. 2021.

BRASIL. Presidência da República. Casa Civil. Subchefia para Assuntos Jurídicos. Lei № 13.8II, de I2 de março de 2019. Diário Oficial da União, I3 mar. 2019, p. I. Brasília, DF, 2019.

Disponível em: http://www.planalto.gov.br/ccivil_03/_ato2019-2022/2019/lei/Li381r.htm. Acesso em: I2 jun. 2021.

DUTRA, Deo Campos. Método(s) em Direito Comparado. Revista da Faculdade de Direito UFPR, Curitiba, v. 6I, n. 3, p. I89- 212, dez. 2016. Disponível em: https://revistas.ufpr.br/direito/article/view/4662o. Acesso em: io jun. 202I. DOI: http://dx.doi.org/ro.538o/rfdufpr.v6ri3.4662o.

FERNANDES, Anderson Eurico da Costa. O início da personalidade jurídica. Revista Jurídica Luso-Brasileira, Lisboa, v. 7, n. 3, p. I8I-200, 202I. Disponível em: https://www.cidp.pt/revistas/rjlb/202I/3/202I_03_018I_0200.pdf. Acesso em: I3 jun. 202I.

GONÇALVES, Carlos Roberto. Direito Civil Brasileiro: Direito de Família, v. 6. I8 Edição. São Paulo: Saraiva Jur, 202ı. 
JERÓNIMO, Patrícia. Lições de Direito Comparado. Iํㅡㄹ Edição. Gualtar (Braga: Elsa European Law Students' Association: UMinho - Universidade do Minho, 2015.

JUSTO, António Santos. A influência do Direito Português na formação do Direito Brasileiro. Revista Jurídica da FA7, Fortaleza, v. 5, n. I, p. 197-242, abr. 2008. Disponível em:

https://periodicos.uni7.edu.br/index.php/revistajuridica/article/view/217. Acesso em: I4 jun. 2021. DOI: https://doi.org/ro.24067/rjfa7;5.1:217.

NELB. Núcleo de Estudos Luso-Brasileiro. MIP. Inscrição na Ordem dos Advogados. Disponível em: https://nelb.pt/mip/ordemdosadvogados/. Acesso em: I3 jun. 202I.

OVÍDIO, Francisco. Aspectos do Direito Comparado. Revista da Faculdade de Direito, Universidade de São Paulo, v. 79, p. I61-I8o, 1984. Disponível em: https://www.revistas.usp.br/rfdusp/article/view/67009. Acesso em: I3 jun. 202I.

PORTUGAL. Diário da República Eletrônico. Legislação Consolidada. Código Civil. Decreto-Lei N.o 47.344, de 25 de novembro de 1966. Diário do Governo n.o $274 /$ ı666, Série I, de 25 de novembro de 1966. Disponível em: https://dre.pt/legislacao-consolidada//lc/34509075/view. Acesso em: ro jun. 2021.

PORTUGAL. Diário da República Eletrônico. Pesquisa. Decreto-Lei № 496, de 25 de novembro de 1977. Diário da República n.ํ 273/1977, Iํ Suplemento, Série I, de 25 de novembro de 1977. Disponível em: https://dre.pt/home/-/dre/300030/details/maximized. Acesso em: Io jun. 2021.

PORTUGAl. Assembleia da República. Constituição da República Portuguesa. Disponível em: https://www.parlamento.pt/Legislacao/Paginas/ConstituicaoRepublicaPortuguesa.aspx. 
Acesso em: 13 jun. 2021.

PORTUGAL. Ordem dos Advogados. Homepage. Ordem. Regras Profissionais. Disponível em: https://portal.oa.pt/ordem/regras-profissionais/. Acesso em: I4 jun. 202I.

SAVICK. Michele. O Direito Brasileiro: fruto da tradição ou da estagnação? Res Severa Verum Gaudium - Revista Científica dos Estudantes de Direito da UFRGS, Porto Alegre, v. I, n. 2, p. 13-30, nov. 2009. Disponível em: https://seer.ufrgs.br/resseveraverumgaudium/article/view/64157. Acesso em: I7 jun. 202I.

SIDOU, José Maria Othon. O ingresso na Maioridade (à luz do código civil e do direito comparado). Revista da Academia Brasileira de Letras Jurídicas, Rio de Janeiro, v. 2o, n. 26, p. I25-131, jul./dez., 2004. Disponível em: http://www.ablj.org.br/revistas/revista26.asp. Acesso em: 14 jun. 2021.

SIFUENTES, Mônica Jacqueline. O Poder Judiciário no Brasil e em Portugal: reflexões e perspectivas. Revista de Informação Legislativa, Brasília, v. 36, n. I42, p. 324-340, abr./jun. 1999. Disponível em: https://www2.senado.leg.br/bdsf/bitstream/handle/id/494/ri4225. PDF? sequence $=4$. Acesso em: 13 jun. 2021.

UNIVERSIDADE DE LISBOA. Faculdade de Direito. Início. Alunos. Apoio ao aluno. Saídas Profissionais. Profissões Jurídicas. Disponível em: http://www.fd.ulisboa.pt/alunos/apoio-ao-aluno/saidas-profissionais/profissoes juridicas/. Acesso em: 13 jun. 2021. 